\title{
Lung and chest wall mechanics in patients with acquired immunodeficiency syndrome and severe Pneumocystis carinii pneumonia
}

\author{
E. D'Angelo*, E. Calderini**, F.M. Robatto*, P. Puccio**, J. Milic-Emili*
}

\begin{abstract}
Lung and chest wall mechanics in patients with acquired immunodeficiency syndrome and severe Pneumocystis carinii pneumonia. E. D'Angelo, E. Calderini, F.M. Robatto, P. Puccio, J. Milic-Emili. COERS Journals Ltd 1997.

ABSTRACT: The aim of this study was to assess the mechanical characteristics of the respiratory system in patients with acquired immune deficiency syndrome (AIDS) and acute respiratory distress syndrome (ARDS) caused by Pneumocystis carinii pneumonia (PCP).

In 12 mechanically ventilated patients, total respiratory system mechanics was assessed using the technique of rapid airway occlusion during constant flow inflation, and was partitioned into lung and chest wall components using the oesophageal balloon technique. We measured interrupter resistance $(R$ int $)$, which mainly reflects airway resistance, additional resistance $(\Delta R)$ due to viscoelastic behaviour and time constant inequalities, and static elastance $\left(E_{\text {st }}\right)$. In addition, the static inflation volume-pressure $(V-P)$ curve was assessed. In eight patients, computed tomography scans were performed within 2 days of the assessment of respiratory mechanics.

Compared to values reported in the literature for normal subjects, $E$ st and $\Delta R$ were markedly increased in AIDS patients with PCP, whilst Rint exhibited a relatively smaller increase. These changes, which involved only the lung and airways, were mainly due to the reduction of ventilated lung units, but additional factors were involved to cause independent modifications of lung stiffness, airway calibre, and viscoelastic properties. The changes in $R$ int, $\Delta R$, and $E$ st were similar to those observed in other studies on patients with ARDS of different aetiologies. At variance with common observations in the latter patients, none of the AIDS patients with PCP exhibited an inflection point on the static inflation $V-P$ curve, suggesting little or no alveolar recruitment during lung inflation.

This finding could be related to the distinctive histopathology of Pneumocystis carinii pneumonia. Indeed, computed tomography revealed homogeneous diffuse interstitial and alveolar infiltration rather than the dense, dependent opacities observed in other studies on acute respiratory distress syndrome of different aetiologies.
\end{abstract}

Eur Respir J 1997; 10: 2343-2350.

Pneumocystis carinii pneumonia (PCP) is the most frequent severe opportunistic infection in patients with acquired immunodeficiency syndrome (AIDS). It is held responsible for up to $85 \%$ of episodes of acute respiratory failure that occur in AIDS [1] and $80 \%$ of emergency admissions to intensive care units $[2,3]$, with a reported mortality rate of $75-100 \%$ for patients requiring mechanical ventilation [4]. In a recent consensus conference [5], PCP was included, though not by unanimous decision, among the causes of acute respiratory distress syndrome (ARDS), once the following criteria are met: acute onset; arterial oxygen tension $\left(\mathrm{Pa}, \mathrm{O}_{2}\right) /$ inspiratory oxygen fraction $\left(F \mathrm{I}, \mathrm{O}_{2}\right)<27 \mathrm{kPa}(200 \mathrm{mmHg})$; bilateral infiltrates on chest radiographs; and no evidence of left atrial hypertension.

ARDS is characterized by increased microvascular permeability leading to a progressive and widespread accumulation of extravascular water in the lung, associated with inflammatory interstitial infiltration and
*Istituto di Fisiologia Umana I, Università di Milano, Milan, Italy. **Servizio di Anestesia e Rianimazione, DSNP Ospedale San Raffaele, Milan, Italy.

Correspondence: E. D'Angelo Istituto di Fisiologia Umana I via Mangiagalli 32 20133 Milan Italy

Keywords: Acquired immunodeficiency syndrome

adult respiratory distress syndrome inspiratory work respiratory mechanics

Received: January 71997

Accepted after revision June 191997

This research has been supported by the Italian Ministry of University and of Scientific and Technological Research. JM-E was in part supported by the National Research Council of Italy. marked thickening of the alveolar septa $[6,7]$. On the other hand, PCP has a distinctive histopathology: the alveoli are filled with few inflammatory cells and an acellular, eosinophilic, proteinaceous material that contains cysts and trophozoites of the organism, whilst the interstitial spaces contain predominantly mononuclear inflammatory cells $[8,9]$. Presence of fibrosis has also been observed, particularly in severe pneumocystosis [10]. This could lead to peculiar changes in the mechanical properties of the respiratory system.

To our knowledge, no systematic study has been performed on the mechanical properties of the respiratory system of patients with AIDS and PCP requiring artificial ventilation. The aim of this study was, therefore, to assess the mechanical characteristics of the respiratory system and its components in such patients in whom ARDS is due to direct lung injury, and compare the results with those reported in the literature for patients with ARDS due to other causes. 


\section{Materials and methods}

\section{Subjects}

Twelve patients (six males) with AIDS (group IV, subgroup C, according to Centers for Disease Control [11]) admitted to the intensive care unit of the San Raffaele Hospital for management of acute respiratory failure due to $P$. carinii pneumonia were studied. Their mean $( \pm$ SD $)$ age, weight and height were $38 \pm 8$ yrs, $54 \pm$ $8 \mathrm{~kg}$ and $166 \pm 9 \mathrm{~cm}$, respectively; pertinent clinical data are given in table 1. The diagnosis of PCP was obtained bronchoscopically, and $P$. carinii considered the most important pathogen. The patients were treated for PCP with thrimetroprim-sulphamethoxazole (20-100 $\left.\mathrm{mg} \cdot \mathrm{kg}^{-1}\right)$, or pentamidine isethionate $\left(4 \mathrm{mg} \cdot \mathrm{kg}^{-1}\right)$, or trimetrexate $\left(45 \mathrm{mg} \cdot \mathrm{kg}^{-1}\right)$ given intravenously, together with systemic corticosteroids (methylprednisolone, 1.8 $\mathrm{mg} \cdot \mathrm{kg}^{-1}$ for 3 days, then gradually reduced). The conventional criteria for ARDS were met in all cases (table $1)$.

All patients were sedated (thiopental sodium; 2 $\mathrm{mg} \cdot \mathrm{kg}^{-1} \cdot \mathrm{h}^{-1}$ ) and paralysed (pancuronium bromide; 2 $\mathrm{mg} \cdot \mathrm{kg}^{-1} \cdot \mathrm{h}^{-1}$ ), on the decision of the primary physician. They were nasotracheally intubated with a cuffed endotracheal tube (Mallinckrodt Medical, Athlow, Ireland; 7-8.5 mm internal diameter, 30-36 cm long) and mechanically ventilated (Siemens Servo Ventilator 900C; Berlin, Germany) in the semirecumbent position. The investigation was approved by the Institutional Ethics Committee and informed consent was obtained from the patients (prior to sedation) or their next of kin. During the study, a physician unconnected with the experimental protocols was always present to provide patient care.

\section{Procedures}

The ventilator settings (on intermittent mandatory ventilation (IMV) mode) consisted of a fixed tidal vol- ume $(V \mathrm{~T})(0.43 \pm 0.07 \mathrm{~L})$, a fixed inspiratory flow $(0.53 \pm 0.07$ $\left.\mathrm{L} \cdot \mathrm{s}^{-1}\right)$, and a respiratory frequency of 14 breaths $\cdot \mathrm{min}^{-1}$. A short $(0.4 \mathrm{~s})$ end-inspiratory pause was automatically induced on a breath-by-breath basis by the ventilator, while longer ( $5 \mathrm{~s})$ end-inspiratory pauses were intermittently (3-4 times) produced by pressing the endinspiratory hold button. The transistor-transistor logic signal of the ventilator operated a normally open solenoid valve, which was placed in the breathing circuit between the Y-connector and the pneumotachograph. The closing time of the valve ranged $10-15 \mathrm{~ms}$ depending on the peak pressure in the inspiratory line. The equipment dead space (not including the endotracheal tube) was $150 \mathrm{~mL}$. Special care was taken to avoid air leaks around the tracheal cuff and from the breathing circuit. A single length of standard low-compliance adult tubing ( $2 \mathrm{~cm}$ internal diameter, $110 \mathrm{~cm}$ long) was used to minimize errors in mechanics measurements.

Four patients were studied at zero end-expiratory pressure (ZEEP), whilst positive end-expiratory pressure (PEEP; $4.9 \pm 1.1 \mathrm{cmH}_{2} \mathrm{O}$ ) was applied to the other patients. Changes in end-expiratory lung volume due to PEEP were measured by removing the Y-piece of the ventilator from the pneumotachograph and allowing the patient to exhale until flow ceased. Intrinsic PEEP was not present, as flow became nil at end-expiration and no changes in tracheal pressure $(P \operatorname{tr})$ occurred on performing end-expiratory airway occlusions.

In order to assess the expiratory reserve volume (ERV) and the vital capacity (VC), the patients were temporarily connected via the pneumotachograph to a large syringe $(2.5 \mathrm{~L})$. Starting from end-expiratory lung volume, a gentle aspiration was first performed until $P$ tr became stable in the range $-15--25 \mathrm{cmH}_{2} \mathrm{O}$, and then the lungs were inflated until $P$ tr plateaued at values ranging $40-45 \mathrm{cmH}_{2} \mathrm{O}$.

$P$ tr was measured via an end-sealed, noncompliant, polyethylene catheter connected to a pressure transducer (1290A; Hewlett Packard, Andover, MA, USA). The catheter $(1.5 \mathrm{~mm}$ internal diameter, $50 \mathrm{~cm}$ long) had a sealed end and multiple holes in the distal $3 \mathrm{~cm}$ and

Table 1. - Clinical characteristics of study population at enrolment

\begin{tabular}{|c|c|c|c|c|c|c|c|c|c|}
\hline $\begin{array}{l}\text { Patient } \\
\text { No. }\end{array}$ & $\begin{array}{l}\text { Transmission } \\
\text { factor }\end{array}$ & $\begin{array}{c}\text { PCP } \\
\text { episode }\end{array}$ & $\begin{array}{c}\text { Other } \\
\text { organism } \\
\text { in BAL }\end{array}$ & $\begin{array}{l}\text { Intubation } \\
\text { days }\end{array}$ & LIS & $\begin{array}{c}P_{\mathrm{a}, \mathrm{O}_{2}} / F \mathrm{I}, \mathrm{O}_{2} \\
\mathrm{mmHg}\end{array}$ & $\begin{array}{l}{\mathrm{Pa}, \mathrm{CO}_{2}}_{2} \\
\mathrm{mmHg}\end{array}$ & $\begin{array}{c}\text { Arterial } \\
\mathrm{pH}\end{array}$ & $\begin{array}{l}\mathrm{LDH} \\
\mathrm{U} \cdot \mathrm{L}^{-1}\end{array}$ \\
\hline 1 & Homo & $1 \mathrm{st}$ & M. pneumoniae & 2 & 3.0 & 84 & 50 & 7.32 & 763 \\
\hline 2 & IVDA & $1 \mathrm{st}$ & & 3 & 2.6 & 68 & 49 & 7.30 & 2524 \\
\hline 3 & IVDA & $1 \mathrm{st}$ & P. aeruginosa & 11 & 2.7 & 132 & 46 & 7.35 & 1808 \\
\hline 4 & IVDA & $1 \mathrm{st}$ & C. alba & 9 & 3.3 & 75 & 52 & 7.26 & 1161 \\
\hline 5 & Homo & 2nd & S. epidermis & 1 & 2.3 & 99 & 55 & 7.35 & 1397 \\
\hline 6 & Hetero & 2nd & P. aeruginosa & 1 & 2.8 & 78 & 32 & 7.44 & 677 \\
\hline 7 & IVDA & $1 \mathrm{st}$ & & 1 & 2.3 & 138 & 34 & 7.40 & 1625 \\
\hline 8 & Hetero & $1 \mathrm{st}$ & & 4 & 2.5 & 172 & 50 & 7.21 & 1305 \\
\hline 9 & IVDA & $1 \mathrm{st}$ & S. aureus & 4 & 2.3 & 67 & 47 & 7.30 & 1973 \\
\hline 10 & IVDA & $1 \mathrm{st}$ & & 3 & 2.3 & 70 & 37 & 7.32 & 1738 \\
\hline 11 & Hetero & $1 \mathrm{st}$ & CMV & 1 & 2.7 & 58 & 33 & 7.36 & 1515 \\
\hline 12 & Homo & $1 \mathrm{st}$ & & 2 & 3.0 & 87 & 31 & 7.56 & 900 \\
\hline Mean & & & & 3.5 & 2.7 & 94 & 43 & 7.35 & 1449 \\
\hline SD & & & & 3.4 & 0.3 & 35 & 9 & 0.09 & 535 \\
\hline
\end{tabular}

PCP: Pneumocystis carinii pneumonia; BAL: bronchoalveolar lavage; $P_{a}, \mathrm{O}_{2}$ : arterial oxygen tension; $F \mathrm{I}, \mathrm{O}_{2}$ : inspiratory oxygen fraction; $P \mathrm{P}_{\mathrm{a}} \mathrm{CO}_{2}$ : arterial carbon dioxide tension; LDH: lactate dehydrogenase; LIS: lung injury score according to MuRRAY et al. [1]. Homo: homosexual; Hetero: heterosexual; IVDA: intravenous drug abuser; M.: Mycoplasma; P.: Pseudomonas; $C .:$ Candida; S.: Staphylococcus; CMV: cytomegalovirus. $1 \mathrm{mmHg}=0.133 \mathrm{kPa}$. 
protruded $\sim 4 \mathrm{~cm}$ from the endotracheal tube into the trachea. Oesophageal pressure $\left(P_{\text {oes }}\right)$ was measured with a similar transducer connected to a thin-walled latex balloon (8 cm long), filled with $0.5-1.0 \mathrm{~mL}$ of air through a polyethylene catheter $(2 \mathrm{~mm}$ internal diameter, 110 $\mathrm{cm}$ long), with multiple holes over the balloon length. With this system, pressure measurements were not affected by phase shift or alteration in amplitude up to 20 Hz. Flow $\left(V^{\prime}\right)$ was measured with a heated pneumotachograph (Fleisch No. 2; Lausanne, Switzerland) connected to the breathing circuit via a cone, and to a differential pressure transducer (Validyne $\mathrm{MP}-45, \pm 2 \mathrm{cmH}_{2} \mathrm{O}$; Northridge, CA, USA). The response of the pneumotachograph, which was calibrated with the experimental gas mixture, was linear over the experimental range of flows. All signals were recorded on a four-channel pen recorder (7754B; Hewlett-Packard, Cupertino, CA, USA) at a paper speed of $10 \mathrm{~mm} \cdot \mathrm{s}^{-1}$. Moreover, they were sampled at $200 \mathrm{~Hz}$ by a 12-bit analogue-to-digital converter and stored on a personal computer for subsequent data analysis. Changes in lung volume were then obtained by numerical integration of the flow signal.

The arterial oxygen and carbon dioxide tension $\left(\mathrm{Pa}_{\mathrm{a}} \mathrm{CO}_{2}\right)$ and $\mathrm{pH}(\mathrm{pHa})$ were measured with a blood gas analyser (IL BG3; Instrumentation Laboratories, Lexington, MA, USA). The electrocardiogram, cardiac frequency, systemic arterial pressure, arterial oxygen saturation $\left(\mathrm{Sa}_{\mathrm{a}} \mathrm{O}_{2}\right)$, and end-tidal carbon dioxide tension were continuously monitored (Merlino 56S; Hewlett-Packard, Cupertino, CA, USA). These parameters remained nearly constant throughout the experimental session.

In eight patients, thoracic computed tomography (CT) scans were performed within 2 days of the experimental recordings. A Siemens Somatom CR scanner (Siemens Elema AB, Berlin, Germany) was employed; 20-30 exposures, depending on patient size, were taken at 150 $\mathrm{kV}, 50 \mathrm{~mA}$, and $5 \mathrm{~s}$.

\section{Data analysis}

Respiratory mechanics were assessed by means of the constant flow rapid airway occlusion method [12, 13]. Briefly, end-inspiratory airway occlusions were followed by a rapid initial drop in $P$ tr and $P_{\text {oes }}$ (maximal pressure $\left(P_{\max }\right)$ - pressure at airway occlusion $\left.\left(P_{1}\right)\right)$ and, during the long-lasting occlusions, by a slow decay to an apparent plateau value. These plateau pressures, computed as the mean of the values recorded between 3.3 and $3.7 \mathrm{~s}$ after the occlusion, were taken to represent the static end-inspiratory elastic recoil pressure of the respiratory system $(P$ rs,st $)$ and chest wall $\left(P_{\mathrm{w}, \mathrm{st}}\right)$, respectively. The rapid pressure drop in $P$ oes became evident only after $30-35$ breaths were averaged [14]; to this end, the signals of the individual breaths were superimposed at the onset of airway occlusion as detected on the flow trace. Both $P \operatorname{tr}$ and $P$ oes showed some oscillations after airway occlusion; these were allowed for by fitting a smooth curve to the pre- and post-occlusion portions of the pressure signal and by extrapolating the fitted curves to the point in time at which the valve was half-closed to obtain $P_{\max }$ and $P 1$, respectively. The rapid pressure drops in $P$ tr and $P$ oes divided by the flow preceding the occlusion yield the interrupter resistance of the respiratory system $(\Delta R$ int,rs $)$ and chest wall $(\Delta R$ int,w), respectively. The slow pressure drops in $P$ tr and $P$ oes divided by the flow preceding the occlusion yield the additional interrupter resistance of the respiratory system $(R$ int,rs) and chest wall $(R$ int,w), respectively. Finally, $P_{\mathrm{rs}, \mathrm{st}}$ and $P_{\mathrm{w}, \mathrm{st}}$ divided by the inflation volume yield the elastance of the respiratory system $\left(E_{\mathrm{rs}, \mathrm{st}}\right)$ and chest wall $\left(E_{\mathrm{w}, \mathrm{st}}\right)$, respectively. For the lung, the various parameters were computed as the difference between corresponding values of the respiratory system and the chest wall.

In seven subjects, the total inspiratory work per breath $\left(W_{\mathrm{I}}\right)$ and its components, namely static work ( $\left.W_{\text {st }}\right)$, dynamic work due to viscous resistance ( $W$ dyn) and additional tissue resistance $(\Delta W)$, were assessed as previously described $[12,13,15]$. To this end, $P \max , P 1$ and $P$ rs,st were also measured during 3-4 breaths in which the inflation volume was reduced to $0.27 \pm 0.03$ and $0.14 \pm 0.03 \mathrm{~L}$, respectively, while keeping inflation flow unchanged. All these measures were taken at ZEEP.

In order to take into account the effects of anaesthesia and paralysis, the predicted normal values for VC in awake, supine subjects from QuANJER [16] were corrected according to the following equation computed from data obtained by JuNO et al. [17]:

\section{Change in VC $(\Delta \mathrm{VC})=23.9-0.074 \cdot$ age-90.7 $\cdot$ weight/height}

where the reduction of $\mathrm{VC}$ is expressed as a percentage of VC while awake and supine, age is expressed in years, weight in kilograms, and height in centimetres.

Values are presented as mean \pm SD. Regression analysis was performed using the least-square method and analysis of variance (ANOVA). Comparison with data obtained in ARDS patients without AIDS and PCP or normal subjects was made by means of Student's unpaired t-test, and a p-value of less than or equal to 0.05 was accepted as statistically significant. Such comparisons were made with previous results on ARDS patients [18-23] and normal subjects [12] obtained under similar ventilator settings to those of the present study.

\section{Results}

The average value of the $\mathrm{Pa}, \mathrm{O}_{2} / F \mathrm{I}, \mathrm{O}_{2}$ ratio was rather low in the present patients (table 1 ). Indeed, mean arterial $\mathrm{Pa}, \mathrm{O}_{2}$ was only $10 \pm 2 \mathrm{kPa}(76 \pm 16 \mathrm{mmHg})$, in spite of the relatively high $F \mathrm{I}_{2} \mathrm{O}_{2}(0.87 \pm 0.21)$.

In all patients, VC was markedly reduced $(1.54 \pm 0.30$ and $1.55 \pm 0.32 \mathrm{~L}$ for the ZEEP and PEEP group, respectively). These corresponded to $35.6 \pm 7.5$ and $40.5 \pm$ $8.7 \%$ of the predicted values, and did not differ significantly from each other.

Figure 1 shows the relationship between lung volume, expressed as a percentage of measured VC, and $P$ tr observed under static conditions in the ZEEP and PEEP group, respectively. Tidal ventilation occurred between $17 \pm 5$ and $48 \pm 7 \%$ VC in the ZEEP group, and between $28 \pm 10$ and $59 \pm 17 \%$ VC in the PEEP group. These two relationships were almost superimposed along the same volume-pressure $(V-P)$ function, suggesting that low levels of PEEP do not change the mechanical characteristics of the respiratory system in AIDS patients 


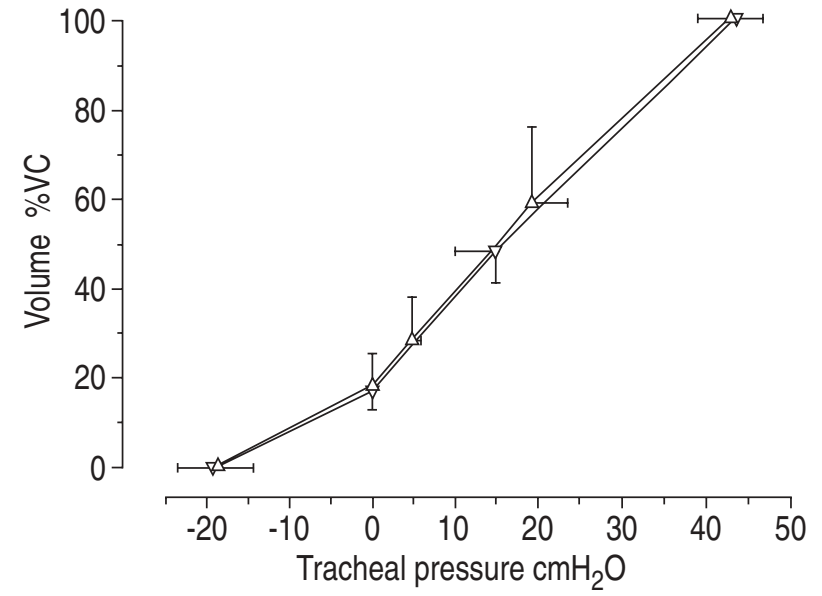

Fig. 1. - Average static volume-pressure relationships of relaxed respiratory systems in four patients at zero end-expiratory pressure (ZEEP; $\nabla$ ) and eight patients on $4.9 \mathrm{~cm} \mathrm{H}_{2} \mathrm{O}$ positive end-expiratory pressure (PEEP; $\Delta$ ). VC: vital capacity. Values are mean \pm SD.

with PCP. Because of this, and since no statistical difference was found for any mechanical parameter between the ZEEP and PEEP group, the data from the two groups were pooled; these mean values are reported in table 2 for the respiratory system, and in table 3 for the lung and chest wall.

The values of Ers,st and Ers,dyn were $36.2 \pm 8.8$ and $43.9 \pm 11.1 \mathrm{cmH}_{2} \mathrm{O} \cdot \mathrm{L}^{-1}$, and those of Rint,rs and additional resistance of the respiratory system $(\Delta R \mathrm{rs}) 4.8 \pm 3.9$ and $6.8 \pm 3.1 \mathrm{cmH}_{2} \mathrm{O} \cdot \mathrm{s} \cdot \mathrm{L}^{-1}$, respectively. The values of $E_{\mathrm{w}, \mathrm{st}}$

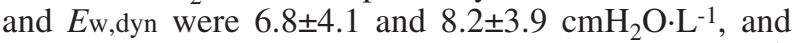
those of $R$ int,w and $\Delta R \mathrm{w} 0.3 \pm 0.1$ and $1.2 \pm 0.4 \mathrm{cmH}_{2} \mathrm{O} \cdot \mathrm{L}^{-1}$, respectively. The values of static and dynamic elastance of the lung ( $E$ L,st and $E$ L,dyn, respectively) were $29.4 \pm$ 8.1 and $35.7 \pm 10.7 \mathrm{cmH}_{2} \mathrm{O} \cdot \mathrm{L}^{-1}$, while interrupter resistance of the lung (Rint,L) and additional resistance of the lung $(\Delta R \mathrm{~L})$ amounted to $4.5 \pm 3.8$ and $5.6 \pm 2.9 \mathrm{cmH}_{2} \mathrm{O} \cdot \mathrm{s} \cdot \mathrm{L}^{-1}$, respectively.

\section{Inspiratory work}

Figure 2 illustrates the relationship of changes in volume to those in tracheal and oesophageal dynamic pressure $(P$ dyn $)$ during inflation at baseline tidal volume obtained in a representative patient. The inspiratory work done on the respiratory system $\left(W_{\mathrm{rs}}\right)$ and chest a)

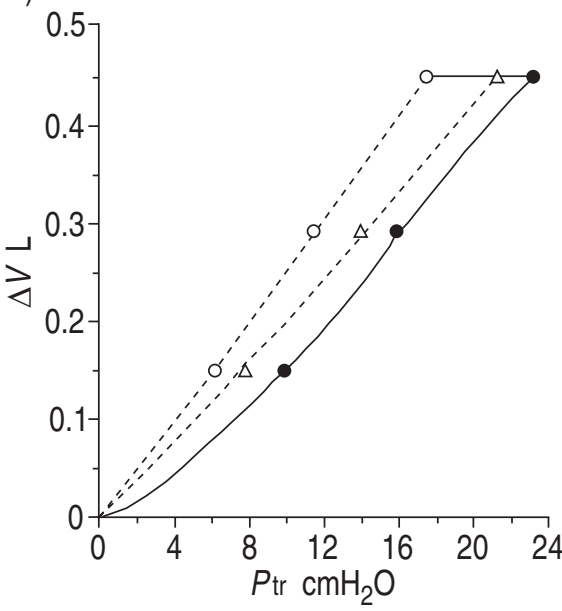

b)

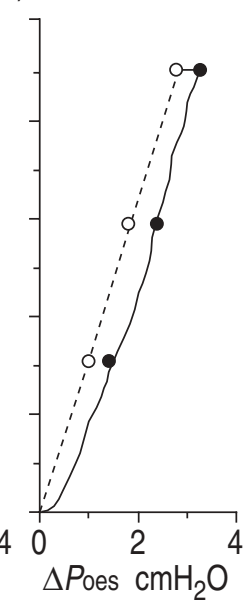

Fig. 2. - Measurements, in a representative patient, of: a) tracheal pressure $(P \operatorname{tr})$; and b) oesophageal pressure $(P$ oes $)$, as a function of inflation volume $(\Delta V)$. $\bullet$ : dynamic pressure; 0 : static pressure; $\Delta$ : pressure at airway occlusion; ——: curve obtained during constant flow inflation; - - - : curve obtained by linear interpolation between experimental points.

Table 2. - Static elastance (Est), interrupter resistance ( $R \mathrm{int})$, and additional resistance of respiratory system ( $\Delta R \mathrm{rs})$ in acute respiratory distress syndrome (ARDS) patients and normal subjects

\begin{tabular}{|c|c|c|c|c|c|c|c|c|}
\hline [Ref.] & $\begin{array}{l}\text { Subject } \\
\text { condition }\end{array}$ & $\begin{array}{l}\text { Age } \\
\text { yrs }\end{array}$ & $\begin{array}{c}\text { Subjects } \\
\mathrm{n}\end{array}$ & $\begin{array}{c}\text { PEEP } \\
\mathrm{cmH}_{2} \mathrm{O}\end{array}$ & $\begin{array}{l}\mathrm{PEEPi} \\
\mathrm{cmH}_{2} \mathrm{O}\end{array}$ & $\begin{array}{c}E_{\text {st }} \\
\mathrm{cmH}_{2} \mathrm{O} \cdot \mathrm{L}^{-1}\end{array}$ & $\begin{array}{c}\quad R \text { int } \\
\mathrm{cmH}_{2} \mathrm{O} \cdot \mathrm{s} \cdot \mathrm{L}^{-1} \\
\end{array}$ & $\begin{array}{c}\Delta R \mathrm{rs} \\
\mathrm{cmH}_{2} \mathrm{O} \cdot \mathrm{s} \cdot \mathrm{L}^{-1}\end{array}$ \\
\hline Present study & ARDS & $38 \pm 8$ & 12 & $0-5$ & 0 & $36.2 \pm 8.8^{* * *}$ & $4.8 \pm 3.9 *$ & $6.8 \pm 3.1 * * *$ \\
\hline [18] & ARDS & $39 \pm 19$ & 7 & 0 & 0 & $33.5 \pm 6.6 * * *$ & $1.7 \pm 1.0$ & $3.8 \pm 1.8^{+}$ \\
\hline [19] & ARDS & $61 \pm 11$ & 8 & 0 & - & $32.2 \pm 7.9 * * *$ & $4.7 \pm 1.1 * * *$ & $8.8 \pm 2.9 * * *$ \\
\hline [20] & ARDS & $33 \pm 16$ & 11 & 5 & 0 & $41.5 \pm 16.8 * * *$ & $2.1 \pm 0.8$ & $3.1 \pm 1.2^{+}$ \\
\hline [21] & ARDS & $54 \pm 20$ & 6 & 0 & $4.6 \pm 6.1$ & $30.9 \pm 13.4 * *$ & $4.2 \pm 1.9 *$ & $7.0 \pm 2.4 * * *$ \\
\hline [22] & ARDS & $61 \pm 9$ & 9 & 5 & $3.5 \pm 0.3$ & $31.6 \pm 8.4 * * *$ & $5.0 \pm 1.2 * * *$ & $8.5 \pm 3.0 * * *$ \\
\hline [23] & ARDS & $62 \pm 10$ & 8 & 5 & 0 & $36.2 \pm 8.7 * * *$ & $3.9 \pm 1.9 *$ & $5.2 \pm 1.1 * * *$ \\
\hline [12] & Normal & $31 \pm 8$ & 16 & 0 & 0 & $14.6 \pm 2.2$ & $2.2 \pm 0.5$ & $2.9 \pm 0.8$ \\
\hline
\end{tabular}

Values are mean \pm SD. PEEP: positive end-expiratory pressure; PEEPi: intrinsic positive end-expiratory pressure; $*, * *, * * *: p<0.05$, $\mathrm{p}<0.01, \mathrm{p}<0.001$, compared to normal values; +' significantly higher $(\mathrm{p}<0.01)$ than values for normal subjects obtained in the same study.

Table 3. - Static elastance (Est), interrupter resistance ( $R$ int), and additional resistance $(\Delta R)$ of lung and chest wall in acute respiratory distress syndrome (ARDS) patients and normal subjects

\begin{tabular}{|c|c|c|c|c|c|c|c|c|c|}
\hline \multirow[t]{2}{*}{ [Ref.] } & \multirow{2}{*}{$\begin{array}{l}\text { Subject } \\
\text { condition }\end{array}$} & \multirow{2}{*}{$\begin{array}{l}\text { Age } \\
\text { yrs }\end{array}$} & \multirow{2}{*}{$\begin{array}{c}\text { Subjects } \\
n\end{array}$} & \multicolumn{3}{|c|}{ Lung } & \multicolumn{3}{|c|}{ Chest wall } \\
\hline & & & & $\begin{array}{c}E_{\mathrm{st}} \\
\mathrm{cmH}_{2} \mathrm{O} \cdot \mathrm{L}^{-1}\end{array}$ & $\begin{array}{c}R \text { Rint } \\
\mathrm{cmH}_{2} \mathrm{O} \cdot \mathrm{s} \cdot \mathrm{L}^{-1}\end{array}$ & $\begin{array}{c}\Delta R \\
\mathrm{cmH}_{2} \mathrm{O} \cdot \mathrm{s} \cdot \mathrm{L}^{-1}\end{array}$ & $\begin{array}{c}E_{\text {st }} \\
\mathrm{cmH}_{2} \mathrm{O} \cdot \mathrm{L}^{-1}\end{array}$ & $\begin{array}{c}R \text { Rint } \\
\mathrm{cmH}_{2} \mathrm{O} \cdot \mathrm{s} \cdot \mathrm{L}^{-1}\end{array}$ & $\begin{array}{c}\Delta R \\
\mathrm{cmH}_{2} \mathrm{O} \cdot \mathrm{s} \cdot \mathrm{L}^{-1}\end{array}$ \\
\hline Present & ARDS & $38 \pm 8$ & 12 & $29.4 \pm 8.1 * * *$ & $4.5 \pm 3.8 * * *$ & $5.6 \pm 2.9 * * *$ & $6.8 \pm 4.1$ & $0.3 \pm 0.1$ & $1.2 \pm 0.4$ \\
\hline$[23]$ & ARDS & $62 \pm 10$ & 8 & $23.7 \pm 5.5^{* * *}$ & $4.4 \pm 1.9^{* * *}$ & $3.2 \pm 0.8 * * *$ & $13.2 \pm 5.4 * *$ & & $1.5 \pm 0.9$ \\
\hline$[13]^{*}$ & Normal & $30 \pm 8$ & 18 & $7.9 \pm 1.6$ & $1.1 \pm 0.4$ & $1.9 \pm 0.6$ & $6.1 \pm 1.0$ & $0.4 \pm 0.1$ & $1.1 \pm 0.2$ \\
\hline
\end{tabular}

Values are mean \pm SD. *: except for Rint which is from D'ANGELo et al. [14]; **, ***: $<<0.01, \mathrm{p}<0.001$, compared to normal values. 
wall $\left(W_{\mathrm{w}}\right)$ was computed as the areas subtended by these curves, while that done on the lung $\left(W_{\mathrm{L}}\right)$ was computed as difference $\left(W_{\mathrm{rs}}-W_{\mathrm{w}}\right)$. Also shown in the figure are the relationships obtained by joining the change in volume of gas $(\Delta V)$-static pressure $(P$ st $)$ and $\Delta V$ - $P 1$ data points obtained during airway occlusions performed at different inflation volumes. Total $W_{\mathrm{rs}}$ and $W_{\mathrm{w}}$ was thus partitioned into a static component $\left(W_{\text {st }}\right)$ given by the area subtended by the $\Delta V-P$ st relationships, and a dynamic component ( $W$ dyn) obtained as the difference between total inspiratory work and $W$ st. The static and dynamic components of work done on the lung ( $W$ st, $\mathrm{L}$ and $W$ dyn,L, respectively) were computed as $W_{\text {st,rs }}-W_{\text {st,w }}$ and $W$ dyn,rs- $W$ dyn,w, respectively. Dynamic $W$ rs was further partitioned into two components by the $\Delta V-P 1$ relationship, the difference between $P$ dyn and $P 1$ along the horizontal axis representing the immediate drop in pressure after airway occlusion, and that between $P 1$ and $P$ st the slow decay during the occlusion. The area enclosed between the $\Delta V$-tracheal $P$ dyn $(P$ dyn,tr $)$ and $\Delta V$ tracheal $P 1(P 1$,tr $)$ relationships should essentially represent work done to overcome airway resistance (Waw) $[13,24]$, whilst the difference between $W$ dyn,rs and $W_{\text {aw }}$ reflects the additional work $\left(\Delta W_{\mathrm{rs}}\right)$ done on the respiratory system as a result of time constant inequality and viscoelastic tissue behaviour [12]. Because no immediate drop was discernible on the $P$ oes tracings of single airway occlusions and hence no $\Delta V-P 1$ relationship could be drawn for the chest wall, dynamic inspiratory pressure of the chest wall $(W \mathrm{I}, \mathrm{dyn}, \mathrm{w})$ should essentially represent the additional work done on the chest wall $\left(\Delta W_{\mathrm{w}}\right)$. Finally, the additional inspiratory work done on the lung $(\Delta W \mathrm{~L})$ was computed as $\Delta W_{\mathrm{rs}}-\Delta W_{\mathrm{w}}$.

The individual values for total inspiratory work and its components are reported in table 4 and in figure $3 \mathrm{a}$ together with the corresponding values obtained in 18 normal anaesthetized, paralysed subjects under similar ventilator settings of the present study [13]. Also shown on the right ordinate of figure 3 is the total inspiratory work per litre $\left(W_{\mathrm{I}} / V \mathrm{~T}\right)$. Because $W_{\mathrm{I}}$ is the product of mean pressure applied during inspiration $\left(\bar{P}_{\mathrm{I}}\right)$ and $V \mathrm{~T}$, $W_{\mathrm{I}} / V \mathrm{~T}$ corresponds to $\bar{P}_{\mathrm{I}}$ with respect to volume. Furthermore, because during constant flow inflation $V \mathrm{~T}=$ inspiratory flow $\left(V^{\prime} \mathrm{I}\right)$-inspiratory time $(t \mathrm{I}), W \mathrm{I} / V \mathrm{~T}$ also describes $\bar{P}_{I}$ with respect to the duration of inspiration.

The results in table 4 and figure $3 a$ do not include the inspiratory resistive work due to the endotracheal tubes (Wet). During constant flow inflation, $W$ et is equal to resistance of the endotracheal tubes at a given flow $(R \mathrm{et}) \cdot V$ 'I $\cdot V \mathrm{~T}$. Using the pressure-flow relationships of endotracheal tubes of various internal diameters and standard length (including connectors) measured in vitro,
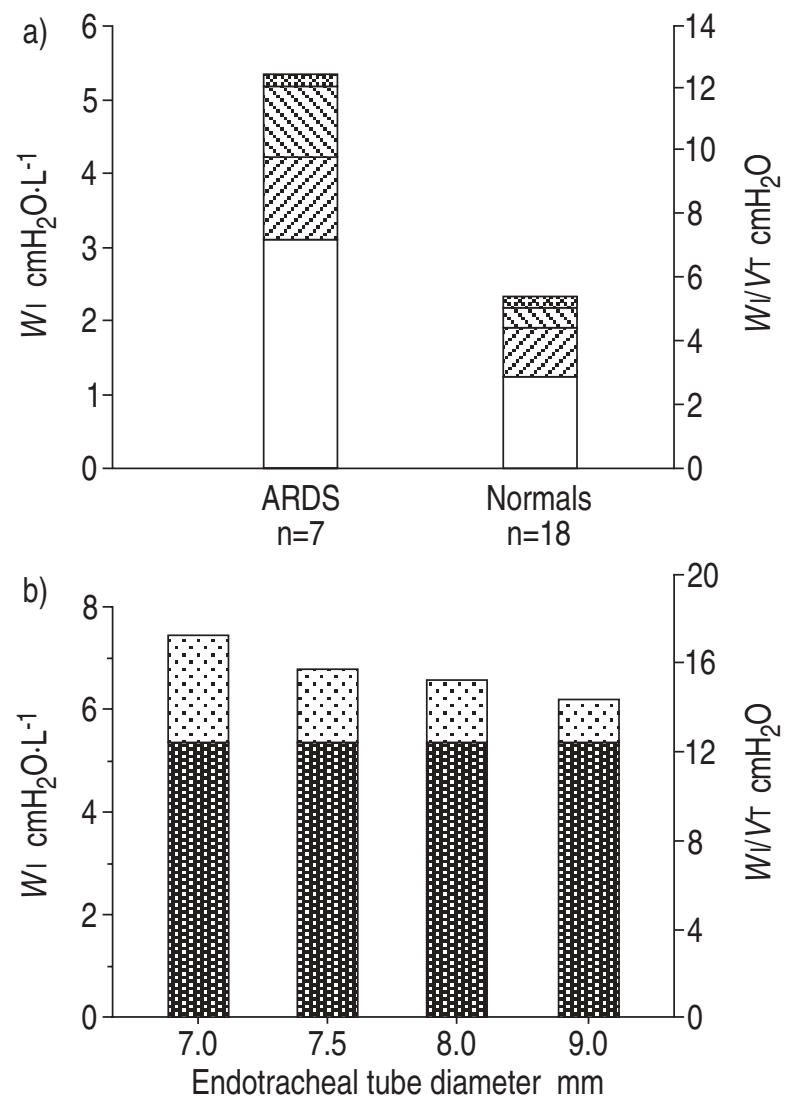

Fig. 3. - a) Mean values of total inspiratory work per breath (WI) and its components in seven acute respiratory distress syndrome (ARDS) patients and 18 normal anaesthetized, paralysed subjects [13] on zero end-expiratory pressure (ZEEP) with inspiratory flow $\left(V^{\prime} \mathrm{I}\right)$ of $0.57 \mathrm{~L} \cdot \mathrm{s}^{-1}$ and tidal volume $(V \mathrm{~T})$ of $0.43 \mathrm{~L} . \square$ : static component of work done on the respiratory system. Dynamic work done on the respiratory system is the sum of work done to overcome airway resistance ( 2$)$ and additional work done on the lung ( 3 ) and chest wall $(\$)$. b) Mean values of $W \mathrm{I}$, partitioned into work done on respiratory system (

corresponding $W$ et values were determined for baseline $V$ 'I $\left(0.57 \mathrm{~L} \cdot \mathrm{s}^{-1}\right)$ and $V$ T $(0.43 \mathrm{~L})$, and were added to the average $W_{\mathrm{I}}$ value of the present patients to obtain the total inspiratory work per breath (fig. 3b). It should be noted that the latter represent theoretical values that would obtain if: a) the tubes had no concrete secretions or kinks that could alter their resistance; and b) the specified tubes had been used.

\section{Discussion}

Compared to normal, anaesthetized, paralysed subjects [12], the present patients exhibited a significantly

Table 4. - Inspiratory work done per breath on the respiratory system (Wrs), and components of the work done on the lung and chest wall during baseline mechanical ventilation in acute respiratory distress syndrome (ARDS) patients and normal subjects

\begin{tabular}{|c|c|c|c|c|c|c|c|}
\hline & \multirow{2}{*}{$\begin{array}{c}\text { Subjects } \\
n\end{array}$} & \multirow{2}{*}{$\begin{array}{c}W \mathrm{rs} \\
\mathrm{cmH}_{2} \mathrm{O} \cdot \mathrm{L}^{-1}\end{array}$} & \multicolumn{2}{|c|}{$W_{\text {st }}$} & \multicolumn{2}{|c|}{$\Delta W$} & \multirow{2}{*}{$\begin{array}{c}\text { Waw } \\
\mathrm{cmH}_{2} \mathrm{O} \cdot \mathrm{L}^{-1}\end{array}$} \\
\hline & & & $\begin{array}{l}\text { Lung } \\
\mathrm{cmH}_{2} \mathrm{O} \cdot \mathrm{L}^{-1}\end{array}$ & $\begin{array}{l}\text { Chest wall } \\
\mathrm{cmH}_{2} \mathrm{O} \cdot \mathrm{L}^{-1}\end{array}$ & $\begin{array}{l}\text { Lung } \\
\mathrm{cmH}_{2} \mathrm{O} \cdot \mathrm{L}^{-1}\end{array}$ & $\begin{array}{l}\text { Chest wall } \\
\mathrm{cmH}_{2} \mathrm{O} \cdot \mathrm{L}^{-1}\end{array}$ & \\
\hline ARDS & 7 & $5.36 \pm 1.34 * * *$ & $2.65 \pm 0.55 * * *$ & $0.46 \pm 0.17$ & $0.97 \pm 0.60 * * *$ & $0.15 \pm 0.08$ & $1.12 \pm 0.66^{*}$ \\
\hline Normals $^{+}$ & 18 & $2.31 \pm 0.11$ & $0.71 \pm 0.06$ & $0.53 \pm 0.07$ & $0.26 \pm 0.08$ & $0.14 \pm 0.03$ & $0.67 \pm 0.09$ \\
\hline
\end{tabular}

Values are mean \pm SD. ${ }^{+}$: from D'ANGELo et al. [13]; *,***: $\mathrm{p}<0.05, \mathrm{p}<0.001$, compared to normal values. $W$ st: static work; $\Delta W$ : additional work; $W$ aw: work done to overcome airway resistance; $W$ rs: work done on the respiratory system. 
increased static elastance and total resistance of the respiratory system, the latter reflecting an increase of Rint and, particularly, of the additional resistance $(\Delta R)$ (table $2)$.

\section{Static inflation V-P curve}

None of our patients exhibited a clearly discernible inflection point on the static inflation $V-P$ curve (figs. 1 and 2). According to some authors [25-27], in ARDS patients without AIDS and PCP the inflection point is a common occurrence, though this might not be particularly frequent according to other studies [22, 2830]. It has been suggested that the inflection is present in the earliest stage of ARDS, whereas later on, probably as a result of oedema resolution, the inflection disappears with or without increases or decreases in elastance, probably depending on the pattern of fibrosis development [26]. Our patients may represent a relatively late stage of ARDS, in spite of the fact that the duration of intubation was short (table 1). Indeed, some reported respiratory symptoms such as cough and increased secretions prior to intubation, and two had had a previous episode requiring mechanical ventilation. On the other hand, it is conceivable that, owing to the peculiar pathogenetic pathways of AIDS-related PCP, inflection points never occur in the static inflation $V-P$ curve of these patients. In fact, the pathological findings of PCP in AIDS patients include interstitial infiltrates associated with alveolar occupation by eosinophilic exudates, hyaline membranes, macrophages, and cellular debris, which oppose recruitment, whilst oedema is moderate or absent $[8,9]$. Moreover, computed tomography scan performed in eight of our patients exhibited homogeneous diffuse interstitial and alveolar infiltration, at variance with what appears to be the most common finding in ARDS patients in whom dense opacities are mainly confined to the dependent lung regions [27]. Because the presence of an inflection point is taken to indicate alveolar recruitment, the present findings suggest that in AIDS patients with ARDS and PCP there is no substantial alveolar recruitment during lung inflation. An alternative explanation is that the recruited areas have a markedly higher elastance than the already ventilated alveoli, though it is difficult to conceive how the sequence of alveolar recruitment could be determined by local elastances in such a way that a lower elastance results in earlier recruitment.

Recently, to prevent low "volume barotrauma" due to mechanical stresses in the event of opening and closing of small airways with each breathing cycle, it has been proposed that in ARDS the applied PEEP should correspond to the pressure at the inflection point [31]. The absence of the inflection point in AIDS patients with PCP does not allow such an adjustment. Thus, in these patients the usefulness of PEEP remains to be established.

\section{Elastance and resistance}

The marked increase of Ers,st is in line with all previous studies on ARDS patients [18-23]. In our patients, the increase of $E$ rs,st was entirely due to increased $E_{\mathrm{st}, \mathrm{L}}$ while Est,w remained within normal limits (table 3). On the other hand, a marked increase of $E_{\text {st,w was found in }}$ ARDS patients by PeLosi et al. [23]; this may reflect different study populations or methodological discrepancies. It is also possible that, as a result of the possible difference in the distribution of lesions within the lungs (see above), the expansion of the chest wall in the patients of Pelosi et al. [23] occurred with greater distortion than in those of the present study.

The marked increase of $\Delta R \mathrm{rs}$ and $R$ int, the latter mainly reflecting increased airway resistance $(R$ aw $)$, is in line with most studies on ARDS patients [19, 21-23]. In two previous studies $[18,20]$, however, both $R$ int and $\Delta R$ rs did not differ significantly from the results obtained on normal, anaesthetized, paralysed subjects by D'ANGELO et al. [12]. The lower values of $\Delta R$ rs found by AuLER et al. [18] and PESENTI et al. [20] are probably due in part to differences in data analysis, since these $\Delta R$ rs values were in any case significantly larger than those obtained by the same authors on normal, anaesthetized, paralysed subjects. Indeed, in the study of AULER et al. [18], computation of the slow decay of $P \operatorname{tr}$ was limited to the first second following the rapid end-inspiratory airway occlusion. However, differences in patient population may also be responsible for the discrepant results, particularly in respect to $R$ int.

In the patients of the present study the values of $E$ rs,st and $\Delta R$ rs were similar at ZEEP and PEEP of $5 \mathrm{cmH}_{2} \mathrm{O}$. This is consistent with the findings in normal subjects [32] and in ARDS patients [22, 23, 28, 29] obtained over a larger PEEP range, but contrasts with the results of FALKE et al. [25], who found a decrease in static elastance $(E$ st $)$ with PEEP of $5 \mathrm{cmH}_{2} \mathrm{O}$. The lack of $E$ rs,st changes with PEEP in the present patients is not surprising because, like normal subjects, they did not exhibit an inflection point on the static inflation $V$ - $P$ curve (figs. 1 and 2) and, as a consequence, there probably was little or no alveolar recruitment with PEEP. On the other hand, in most of the ARDS patients in whom there was evidence of alveolar recruitment with PEEP [22, 23, 28, 29], Ers,st did not change significantly with PEEP of $5-10 \mathrm{cmH}_{2} \mathrm{O}$, and $P$ rs,st at end-inflation was not in the flat portion of the static inflation $V-P$ relationship.

The values of $R$ int in the present patients were also independent of PEEP. This is at variance with findings in normal, anaesthetized, paralysed subjects [12, 14], but consistent with previous observations in ARDS patients $[19,20]$. This discrepancy cannot be attributed to Rint,w because in our patients it was both small and unaffected by PEEP (table 3 ). It is possible that because of the relatively high lung recoil in ARDS patients, further increases in lung volume and $P$ st,L have little effect on the already stretched airways.

In all patients, VC was markedly reduced, as expected in ARDS. Because of absence of inflection points in the static inflation $V-P$ curve, lung units ventilated over the $V \mathrm{~T}$ range should be essentially the same as those ventilated over VC. From the reduction in VC, it is, therefore, possible to predict the increase in $E_{\text {st, } \mathrm{L}}$ and $R$ int,L relative to normal values $[13,14]$, on the assumption that the specific mechanical properties of the lung and airways remain normal (fig. 4). On this basis it can 

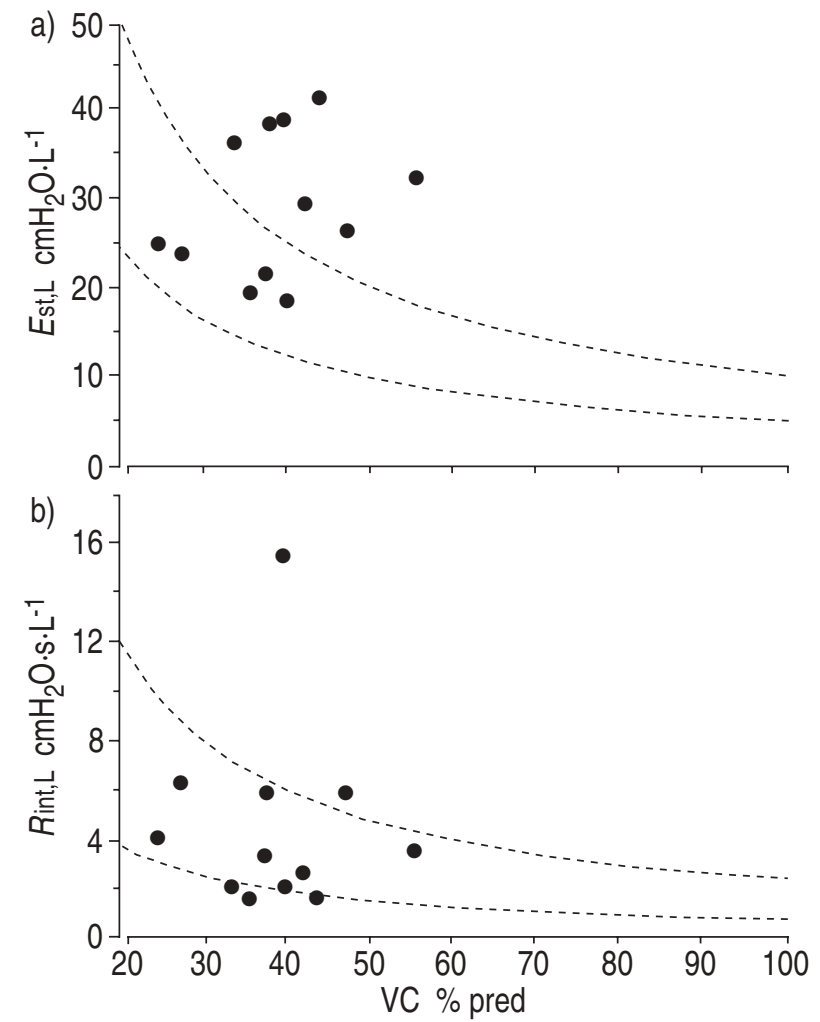

Fig. 4. - Relationship of vital capacity (VC) expressed as percentage of predicted values ( $\%$ pred) to: a) static lung elastance $(E s t, L)$; and $\mathrm{b}$ ) interrupter resistance (Rint,L), in 12 patients. - - : $95 \%$ confidence limits of the relationship expected with normal $E$ st,L and Rint,L (see text for further details).

be concluded that: 1) in five patients the aerated lung units retained nearly normal elastic properties, while in the other seven patients they became stiffer; and 2) airway resistance remained essentially normal in nine patients, increased in two patients, and probably decreased in one patient. Higher than expected values of $E$ st,L could reflect fibrosis [6-10] and/or altered surfactant [33], while the contrasting changes in Rint,L could reflect the interaction of multiple factors (increased lung recoil, release of bronchoconstrictor or bronchodilating agents, intraluminal secretions, peribronchial oedema or infiltrates). That multiple factors with opposite effects were modulating the airway resistance of our patients, besides a reduction in ventilated lung units, is also suggested by the absence of a significant correlation between $E_{\text {st,L }}$ and Rint,L (fig. 5). This, in turn, may explain the occasional finding of an unchanged $R$ int in ARDS patients $[18,20]$.

The increase of $\Delta R \mathrm{rs}$ and $\Delta R \mathrm{~L}$ found in both the present patients, and in others with ARDS, (tables 2 and 3) may also be explained on the basis of the reduction of ventilated lung tissue, because the significant linear relationship between $E_{\text {st, } \mathrm{L}}$ and $\Delta R \mathrm{~L}$ in figure 5 implies an inverse relationship between $\mathrm{VC}$ as a percentage of predicted and $\Delta R \mathrm{~L}$. On the other hand, the correlation coefficient of the former relationship was rather low, suggesting that different factors may affect lung elasticity and viscoelasticity. Therefore, the elastance and the pressure dissipations within the lung tissue may not be inherently coupled, as previously suggested [34].
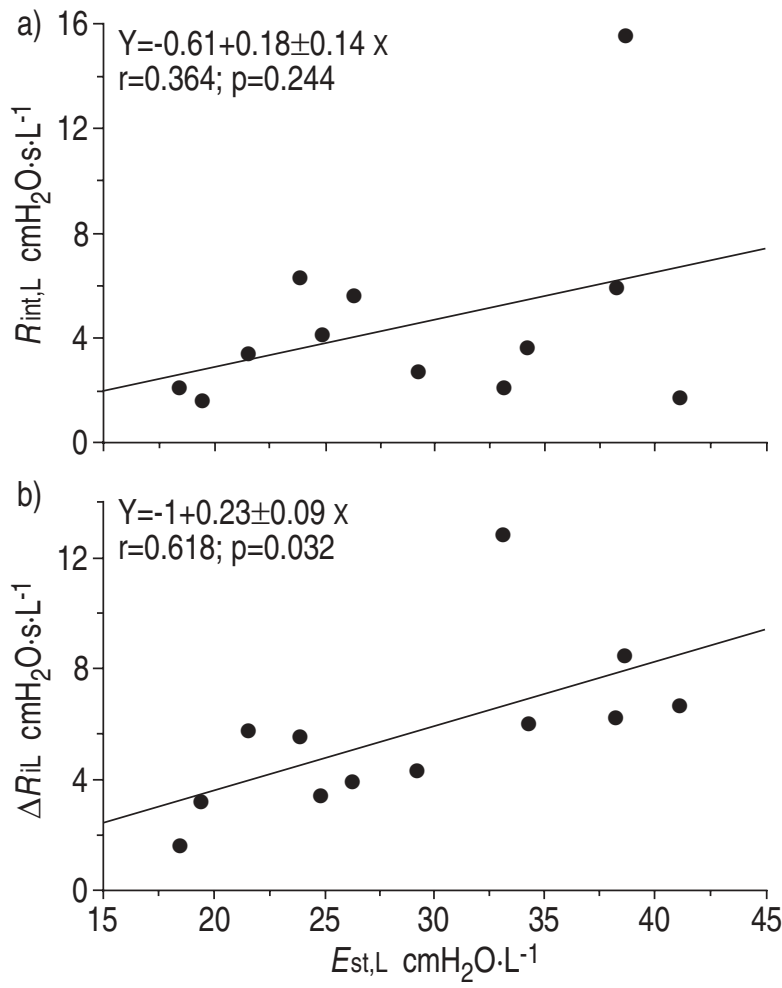

Fig. 5. - Relationship of static lung elastance ( $E$ st,L) to: a) interrupter lung resistance $(R \mathrm{int}, \mathrm{L})$; and $\mathrm{b})$ additional resistance $(\Delta R \mathrm{~L})$, in 12 patients.

\section{Implications on inspiratory muscle fatigue}

During baseline ventilation $W_{I}$ was, on average, $133 \%$ higher in the present ARDS patients than in normal subjects (fig. 3 and table 4). This difference was largely due to increased $W$ st,rs though both $W$ aw and $\Delta W \mathrm{~L}$ were also increased. By contrast, both $W_{\mathrm{st}}$ w and $\Delta W_{\mathrm{w}}$ did not change significantly.

Bellemare and Grassino [35] have shown that the fatigue threshold of the diaphragm depends on its tension-time index $(\mathrm{T} t \mathrm{di})$ and that $\mathrm{T} t \mathrm{di}=(\bar{P} \mathrm{di} \cdot t \mathrm{t} / t \mathrm{tot}) / P_{\mathrm{di}}, \max$, where $\bar{P}_{\mathrm{di}}$ is the mean transdiaphragmatic pressure developed during inspiration, $P$ di,max is the maximal static pressure at functional residual capacity, and $t \mathrm{I} / t$ tot is the inspiratory duty cycle. When Ttdi exceeds a critical value of $\sim 0.15$, diaphragmatic fatigue is likely to occur. For the inspiratory muscles other than the diaphragm the tension-time index $(\mathrm{T} t \mathrm{rcm})=($ mean pleural pressure $\left.\left(\bar{P}_{\mathrm{pl}}\right) \cdot t \mathrm{l} / \mathrm{ttot}\right) /$ maximal pleural pressure $(P \mathrm{pl}, \max )$, and has a critical value of $\sim 0.30$ [36]. According to the data in figure $3 \mathrm{~b}$, the values of $\bar{P}$ I required to sustain the baseline ventilation during spontaneous breathing before intubation should have been $\sim 13 \mathrm{cmH}_{2} \mathrm{O}$, while, given the partition of $W_{\mathrm{I}}$ in table 4 , those of $\bar{P}$ di and $\bar{P}$ pl should have amounted to $\sim 13$ and $11 \mathrm{cmH}_{2} \mathrm{O}$, respectively. Assuming the usual value of $t \mathrm{I} / t$ tot of 0.4 , muscle fatigue would have occurred if $P$ di,max and $P$ pl,max were about 35 and $15 \mathrm{cmH}_{2} \mathrm{O}$, respectively. These predicted values are considerably lower than those that can actually be developed by normal adults of a similar age to the present patients. Though most of these patients had a reduced muscular mass and were malnourished, as evidenced by low body weight and low plasmatic levels of albumin $\left(2.2 \pm 0.2 \mathrm{~g} \cdot 100 \mathrm{~mL}^{-1}\right)$, it is unlikely that 
mechanical ventilation was required because of impending inspiratory muscle fatigue. In fact, mechanical ventilation was instituted because of severe hypoxaemia, tachypnoea and dyspnoea.

\section{References}

1. Murray JF, Garay SM, Hopewell PC, Mills J, Stover DG. NHLBI workshop summary: pulmonary complications of the acquired immunodeficiency syndrome: an update. Am Rev Respir Dis 1987; 135: 504-549.

2. Roger PL, Lane C, Henderson DK, Parrillo J, Masur H. Admissions of AIDS patients to a medical intensive care unit: causes and outcome. Crit Care Med 1989; 17: 113-117.

3. Deam R, Jemberley APS, Anderson DK, Soni N. AIDS in the ICU. Anesthesia 1988; 43: 150-151.

4. Hawley PH, Ronco JJ, Guillemi SA, et al. Decreasing frequency but worsening mortality of acute respiratory failure secondary to AIDS-related Pneumocystis carinii pneumonia. Chest 1994; 106: 1456-1459.

5. Bernard GR, Artigas A, Brigham KL, et al. The AmericanEuropean consensus conference on ARDS: definitions, mechanisms, relevant outcomes, and clinical trial coordination. Am J Respir Crit Care Med 1994; 149: 818-824.

6. Rinaldo JE, Roger GM. Adult respiratory distress syndrome: changing concepts of lung injury and repair. $N$ Engl J Med 1982; 306: 900-909.

7. Petty TL, Fowler AA. Another look at ARDS. Chest 1982; 82: 98-108.

8. Weber WR, Askin FB, Dehner IP. Lung biopsy in Pneumocystis carinii pneumonia: a histopathologic study of typical and atypical features. Am J Clin Pathol 1977; 67: 11-19.

9. Katzenstein ALA. Mycobacterial infections and fungal and protozoal disease. In: Thurlbeck WM, ed. Pathology of the Lung. Stuttgart, NewYork, Georg Thieme Verlag, 1988; pp. 238-246.

10. Walzer PD. Pneumocystis carinii. In: Mandell GL, Bennett JE, Dolin R, eds. Principles and Practice of Infectious Diseases. NewYork, Churchill Livingstone Inc., 1995; pp. 2475-2487.

11. Centres for Disease Control: Revision of the CDC surveillance case definition for acquired immunodeficiency syndrome. MMWR Morb Mortal Wkly Rep 1987; 36 (Suppl. 1): 1-15.

12. D'Angelo E, Calderini E, Torri G, Robatto F, Bono D, Milic-Emili J. Respiratory mechanics in anesthetized paralyzed humans: effects of flow, volume, and time. $J$ Appl Physiol 1989; 67: 2556-2564.

13. D'Angelo E, Robatto F, Calderini E, et al. Pulmonary and chest wall mechanics in anesthetized paralyzed humans. J Appl Physiol 1991; 70: 2602-2610.

14. D'Angelo E, Prandi E, Tavola M, Calderini E, MilicEmili J. Chest wall interrupter resistance in anesthetized paralyzed humans. J Appl Physiol 1994; 77: 883-887.

15. Levy P, Similovski T, Corbeil C, et al. A method for studying the static volume-pressure curves of the respiratory system during mechanical ventilation. J Crit Care 1989; 4: 83-89.

16. Quanjer PhH. Standardized Lung Function Testing. Clin Exp Respir Physiol 1983; 19 (Suppl. 5): 22-27.

17. Juno P, Marsh HM, Knopp TJ, Rehder K. Closing capacity in awake and anesthetized-paralyzed man. $J$ Appl Physiol 1978; 44: 238-244.

18. Auler JOC, Saldiva PHN, Martins MA, Carvalho CRR, Negri EM, Hoelz C. Flow and volume dependence of respiratory system mechanics during constant flow ven- tilation in normal subjects and in adult respiratory distress syndrome. Crit Care Med 1990; 18: 1080-1086.

19. Eissa NT, Ranieri VM, Corbeil C, et al. Analysis of behavior of the respiratory system in ARDS patients: effects of flow, volume and time. J Appl Physiol 1991; 70: 2719-2729.

20. Pesenti A, Pelosi P, Rossi N, Virtuani A, Brazzi L, Rossi A. The effects of positive end-expiratory pressure on respiratory resistance in patients with the adult respiratory distress syndrome and in normal anesthetized subjects. Am Rev Respir Dis 1991; 144: 101-107.

21. Tantucci C, Corbeil C, Chassé M, et al. Flow and volume dependence of respiratory system flow resistance in patients with adult respiratory distress syndrome. Am Rev Respir Dis 1992; 145: 355-360.

22. Eissa NT, Ranieri VM, Corbeil C, Chassé M, Braidy J, Milic-Emili J. Effect of PEEP on the mechanics of the respiratory system in ARDS patients. J Appl Physiol 1992; 73: 1728-1735.

23. Pelosi P, Cereda M, Foti G, Giacomini M, Pesenti A. Alterations of lung and chest wall mechanics in patients with acute lung injury: effects of positive end-expiratory pressure. Am J Respir Crit Care Med 1995; 152: 531-537.

24. Guérin C, Coussa ML, Eissa NT, et al. Lung and chest wall mechanics in mechanical ventilated COPD patients. J Appl Physiol 1993; 74: 1571-1580.

25. Falke KJ, Pontoppidan H, Kumar A, Leith DE, Geffin B, Laver MB. Ventilation with positive end-expiratory pressure in acute lung disease. J Clin Invest 1972; 51: 2315-2323.

26. Matamis D, Lemaire F, Harf A, Brun-Buisson C, Ansquer JC, Atlan G. Total respiratory pressure-volume curves in the adult respiratory distress syndrome. Chest 1984; 86: 58-66.

27. Gattinoni L, Pesenti A, Avalli L, Rossi F, Bombino M. Pressure-volume curve of total respiratory system in acute respiratory failure. Am Rev Respir Dis 1987; 136: 730-736.

28. Ranieri VM, Eissa NT, Corbeil C, et al. Effect of positive end-expiratory pressure on alveolar recruitment and gas exchange in patients with adult respiratory distress syndrome. Am Rev Respir Dis 1991; 144: 544-551.

29. Valta P, Takala J, Eissa NT, Milic-Emili J. Does alveolar recruitment occur with positive end-expiratory pressure in adult respiratory distress syndrome patients? J Crit Care 1993; 8: 34-42.

30. Eissa NT, Ranieri VM, Corbeil C, Chassé M, Braidy J, Milic-Emili J. Effect of positive end-expiratory pressure on the work of breathing in adult respiratory distress syndrome patients. J Crit Care 1992; 7: 142-149.

31. Amato MBP, Barbas CSV, Medeiros DM, et al. Beneficial effects of the "open lung approach" with low distending pressures in acute respiratory distress syndrome. Am J Respir Crit Care Med 1995; 152: 1835-1846.

32. D'Angelo E, Calderini E, Tavola M, Bono D, MilicEmili J. Effect of PEEP on respiratory mechanics in anesthetized paralyzed humans. J Appl Physiol 1992; 73: $1736-1742$.

33. Lewis JF, Jobe AH. Surfactant and the adult respiratory distress syndrome. Am Rev Respir Dis 1993; 147: 218-233.

34. Fredberg JJ, Stamenovic D. On the imperfect elasticity of lung tissue. J Appl Physiol 1989; 67: 2408-2419.

35. Bellemare F, Grassino A. Force reserve of the diaphragm in patients with chronic obstructive pulmonary disease. J Appl Physiol 1983; 55: 8-15.

36. Zocchi L, Fitting JW, Majani U, Fracchia C, Rampulla $\mathrm{C}$, Grassino A. Effect of pressure and timing of contraction on human rib cage muscle fatigue. Am Rev Respir Dis 1993; 147: 857-864. 